Journal of Social and Development Sciences

Vol. 4, No. 1, pp. 24-31, Jan 2013 (ISSN 2221-1152)

\title{
The Effect of Price and Climatic Variables on Maize Supply in Ghana
}

\author{
*Henry De-Graft Acquah, Clement Kweku Kyei \\ University of Cape Coast, Cape Coast, Ghana \\ *dr.henrydegraft@gmail.com
}

\begin{abstract}
This study examines the effect of previous price and climatic variables on maize supply in Ghana. For this purpose, two separate approaches are used: (i) a lag model using the OLS technique and (ii) a quantile regression approach. Results from the lag model indicates that an increase in previous year maize price and previous growing season temperature positively affect current year maize supply. However, an increase in previous growing season rainfall negatively affects current year maize supply. The quantile regression results show that maize supply responds differently to previous maize price and climatic variables across the different quantiles of crop area distribution.
\end{abstract}

Keywords: lag model, quantile regression, maize supply, climatic variables, price, crop area.

\section{Introduction}

The economies of most countries in Sub-Saharan Africa depend heavily on agriculture which provides the main source of food income and employment especially to the rural population. In Ghana, agriculture plays an important role in the economy as it employs about $60 \%$ of the population and contributes to about $30 \%$ of the Gross Domestic Product (GDP) (Ghana Business News, 2011). Therefore, achieving higher growth in the agricultural sector is of utmost concern especially in the face of rising incomes and increasing population growth. Furthermore, formulating agricultural policies targeted at increasing production is critical to meet this rising demand. However, agricultural growth in the recent past has been declining. For instance in 2011, agriculture recorded the lowest growth of $0.8 \%$ compared to other sectors. It is therefore important to understand farmers' production decisions in order to inform policy. According to Mamingi (1996) agricultural supply mainly in the form of area expansion is determined by agricultural price and non-price factors. Price is very important in determining farmers planting decisions as it provides incentives for them to increase production. Hence in order to meet the rising demand and bring about sustained and balanced economic growth, it is paramount to understand the effect of prices on production. Also, non-price factors such as good weather conditions and improving technological and institutional frame leads to shifts in the supply function. This is particularly so, for developing countries where various studies (Patel and Singh, 1994, Dixit, et al., 1998) have shown that farmers response behaviour are influenced more by non-price factors. Among the staples grown in Ghana, maize has been identified as one of the most important within the grains and cereals family. It is cultivated on more than, 991,661 hectares and across all agro ecological regions in Ghana (Statistics, Research and Information Directorate [SRID], 2010).

The crop is widely consumed (94\%) by human and the poultry industry across the country and therefore contributes significantly to food security (Environmental Protection Agency [EPA], 2000). It also contributes over $20 \%$ of the incomes earned by smallholder farmers in Ghana. Although maize supply plays an important role in promoting food security, the factors that determine the supply has not been extensively investigated in Ghana and is not well understood. The basic issue is that the magnitude and direction of the relationship between previous climatic variables, previous price and maize supply is not clearly understood. Furthermore, the issue of how maize supply responds to previous price and climatic factors across various quantiles of crop area distribution has not been examined. How much of the variation in maize supply is explained by previous price and climatic factors across the various quantiles of crop area distribution. In order for policy to be able to predict maize supply response and achieve self sufficiency in maize production in Ghana, it is critical to empirically understand the relationship between maize supply and its determinants such as price, rainfall and temperature. Against this background, this study empirically estimate the effect of previous maize price and climatic variables on maize supply response (maize crop area) using a lag model. Also, to further 
understand how maize supply across the different quantiles of crop area distribution responds to previous price and climatic variables, we employ a quantile regression analysis.

\section{Review of Literature}

Numerous studies have employed different response variables and methods to study agricultural supply. Blanc (2011) estimates the effect of weather and climate on farmers' cropping decisions. He noted that farmers' supply decisions are influenced by weather and climate. Additionally, the regressions show a negative effect of precipitation variability and temperature variability on area allocated to some crops, indicating that, as climate risk increases, farmers participate in other activities or diversify toward other crops. Abdulai and Rieder (1995) empirically investigated the supply of cocoa in Ghana using an error correction model. The model was employed to avoid the familiar partial adjustment model's unrealistic assumption of a fixed target supply based on stationary expectation. The results reveal that cocoa supply is significantly influenced by the real producer price of cocoa, real price of maize, the supply of manufactured goods and the real exchange rate. The supply of cocoa was found to be inelastic both in the short and long runs. However, the elasticities obtained in the study suggest that supply of cocoa is more responsive in a shorter time than thought previously. Jain et al., (2005) considered the Nerlovian lag adjustment model to study the supply response function of oilseeds in the Indian state of Rajasthan. The oilseed crops selected for the study were: groundnut, soybean, rapeseed \& mustard, sesamum and taramira. The final model specified by the authors was of the form;

$A_{t}=b_{0}+b_{1} L P S C+b_{2}$ LASC $+b_{3}$ LYSC $+b_{4}$ YRSC $+b_{5} P R S C+b_{6} L Y C C$

$+b_{7} L P C C+b_{8} R F \_I R R+b_{9} D D+\ldots \ldots \ldots .+V_{t}$

where, $A_{t}=$ Current year area under study crop; LPSC = One year lagged price of the study crop deflated by CPI for agricultural labour ; LASC = One year lagged area of the study crop;

LYSC = One year lagged yield of the study crop;

YRSC = Yield risk of the studied crop measured by standard deviation of three preceding years;

PRSC = Price risk of the studied crop measured by standard deviation of three preceding years; LYCC = Lagged yield competing crop; LPCC = One year lagged competing crop price deflated by CPI for agricultural labour; RF_IRR = Seasonal rainfall and/or irrigated area under study crop; DD = District dummy; $\mathrm{V}_{t}=$ Errorterm.

Ordinary least square method was used to estimate the above acreage response function. The authors found the lagged price variable to be positive in all crops except soybean. The short-run elasticity for the crops ranged from -0.32 in the case of soybean to 0.832 in Taramira. Groundnut and sesamum showed very high long-run elasticities of 1.59 and 1.57 respectively. Also, non-price factors such as yield risk, yield of own and competing crops, rainfall and irrigation facilities considered was found to be relevant explanatory variables. Using an error correction model, Townsend and Thirtle (1997) empirically investigated the production response of small scale producers of maize and cotton crops for communal agriculture in Zimbabwe. The model was employed to avoid spurious regression which arises when variables are cointegrated. According to the authors "most agricultural variables experience a trend over time and a regression of the level of these variables may produce significant results with a high $\mathrm{R}^{2}$ value when indeed no relationship exists". The results of the study showed that the price of maize relative to seed, the number of marketing depots established in the communal areas and the number of loans provided to these farmers are the major factors affecting maize output. Also, the weather was found to have played a significant role in determining the quantity of maize sold.

Using the Nerlovian lagged adjustment model, Madhavan (1972) adopted the acreage as well as yield response to prices for different cereals and cash crops in Tamil Nadu. The author found that the cereal crops responded to variations in yield, while the cash crops were more responsive to variations in prices. Acreage elasticities of commercial crops were higher and hence he suggested the positive price policy to influence the cash crops' acreage and there by the production. However, he posited that the limited supply of land makes it difficult to increase the acreage in response to price increase and hence he was in favour of increasing the output through increasing the yield rather than the acreage. Singh (1998) investigated the supply response of oilseeds in Uttar Pradesh and proxied output decisions of farmers to area under the crop rather than its yield. 
According to the author, the area enjoyed by the crops can be considered as a barometer of the farmers land allocation decision. Furthermore, the area allocation under a crop is a function of several endogenous factors, whereas, the yield is influenced by several exogenous factors. But, he also believed that the farmer could keep area constant and increase output by varying yield level.

\section{Methodology}

Desk research was used to obtain secondary data from the Statistical, Research and Information Directorate (SRID) of the Ministry of Food and Agriculture (MoFA) and the Metrological Services Department of Ghana. The data from SRID included average national maize crop area and yearly maize producer price (per $100 \mathrm{Kg}$ bag). Observed average growing season rainfall and temperature values were obtained from the Metrological Services Department of Ghana. The data set was available over time for the period 1970 to 2010. The most popular and widely used method to estimate supply response functions in developing countries is the Nerlovian model. The basic Nerlovian model is a three equation model. These are

$A_{t}^{*}=a_{0}+a_{1} P_{t}^{e}+a_{2} Z_{t}+u_{t}$

$P_{t}{ }^{e}-P_{t-1}{ }^{e}=B\left(P_{t-1}-P_{t-1}{ }^{e}\right)$

$A_{t}-A_{t-1}=r\left(A_{t}^{*}-A_{t-1}\right)$

where $A_{t}^{*}$ is the desired planted area in the year $t, \mathrm{Pt}_{\mathrm{t}}{ }^{\mathrm{e}}$ is the expected price in the year $\mathrm{t}, \mathrm{Z}_{\mathrm{t}}$ is a vector of exogenous variables in year $t, A_{t}$ and $P_{t}$ are the actual planted area in the year $t$ and the actual price in the year $t$ respectively.

Equation 2 captures a behavioural relationship where the desired planted area is a function of the expected future price and a set of exogenous variables. Equation 3 shows that current expectations are formed by adapting previous expectations given actual achievements (adaptive expectation). B is the expectation coefficient and its value lies between 0 and 1 . Equation 4 is a partial adjustment model implying that desired acreages can differ from the actual area under cultivation due to adjustment lags. $r$ is the Nerlovian coefficient of adjustment which lies between 0 and 1. For equation 2 to be estimated, it is important to eliminate the unobservable variables $\left(\mathrm{A}_{\mathrm{t}}{ }^{*}\right.$ and $\left.\mathrm{P}_{\mathrm{t}} \mathrm{e}\right)$. By substitution and algebraic manipulations, the Nerlovian supply function reduces to the form:

$A_{t}=a_{0}+a_{1} A_{t-1}+a_{2} A_{t-2}+a_{3} P_{t-1}+a_{4} Z_{t}+a_{4} Z_{t-1}-u_{t}$

where the $a$ coefficients are composites of adjustment and expectation coefficients. However, estimation of the Nerlove model comes with some problems. According to Nerlove, 1958a when both partial adjustment and adaptive price expectations are included in the model, it is not possible to estimate the long-run elasticities unless certain restrictions are applied. Notwithstanding, some of the estimation problems can be addressed by modifying the original model (Leaver, 2004).

In this study we employ a lag model which relates maize supply response to previous maize price and previous climatic variables. The supply response variable used is maize crop area. The general form of the model is:

$$
Y_{t}=\operatorname{Pr} \text { ice }_{t-1}+\text { Rain }_{t-1}+\text { Tempt }_{t-1}+\varepsilon_{t}
$$

where $Y_{t}$ is the maize supply response variable at year $t$, Price $t-1$ is previous years maize price, Rain ${ }_{t-1}$ and Tempt $_{\mathrm{t}-1}$ represent previous years weather (Rainfall and Temperature) and $\varepsilon_{\mathrm{t}}$ is the residual term. These two climatic variables are considered in the model since they are the only climatic variables observable by farmers. Therefore, this two measures are the most likely weather variables to influence farmers' decisions to grow a certain crop and the area allocated to it (Blanc, 2011). Maize crop area and maize price are logged to improve their distributions but the climatic variables are not in order to produce semi-elasticities. Some variables are not considered in the model because of data limitations and estimation problems. A time series analysis is used since the data set was available over time. The presence of unit root is tested using the unit root test proposed by Elliott-Rothenberg- Stock (ERS) (Elliott et. al, 1996). This test is preferred because of its greater power and because it performs better with small samples. The ERS test has a null hypothesis of a unit root and an alternative hypothesis of stationarity. The maximum lag length was first chosen according to the proposal of Schwert (1989). To deepen our understanding on how maize supply across the different 
quantiles of crop area distribution responds to previous price and climatic variables, we employ a quantile regression analysis. Quantile regression was first introduced by Koenker and Bassett $(1978$; 1982) as a robust alternative to least-squares regression. In quantile regression, quantiles of the conditional distribution of the dependent variable are expressed as a function of observed covariates. Quantile regression offers a number of advantages over least-squares methods. For instance, quantile regression does not require the restrictive assumptions of least-squares regression (assumes that the error terms are iid, normally distributed, and homoskedastic). Furthermore, since quantile regression estimates quantiles of the conditional distribution rather than the mean, it is more resistant to outliers than least-squares methods (Leider, 2012). The general form of the quantile regression function is specified as:

$$
Y_{t}=X_{t-1} \beta+\varepsilon_{\tau} \quad \text { With Quant }{ }_{\tau}\left(\mathrm{Y}_{\mathrm{t}} \mid \mathrm{X}_{\mathrm{t}-1}\right)=\mathrm{X}_{\mathrm{t}-1} \beta
$$

where Quant $\tau_{\tau} \quad\left(\mathrm{Y}_{\mathrm{t}} \mid \mathrm{X}_{\mathrm{t}-1}\right)$ represents the $\tau^{\text {th }}$ conditional quantile (for this study we consider 0.10, 0.25, 0.50, 0.75 and 0.95 ) of crop area and $\mathrm{X}_{\mathrm{t}-1}$ represents the set of independent variables lagged once. With this specification, quantile regression provides a flexible way for us to explain how a given quantile of crop area changes as a result of changes in previous maize prices and climatic variables.

\section{Results and Discussion}

ERS unit root test was conducted to examine the time series properties of the variables of study. The null hypothesis of a unit root is rejected for the climatic variables and the first-differenced price and crop area variables. Table 1 and Table 2 displays the results of the unit root tests for the price and crop area variables and climatic variables respectively.

Table 1: ERS unit root test (with constant and trend) for price and crop area

\begin{tabular}{lllll}
\hline Variable & Level & Critical value & First difference & Critical value \\
\hline Price & $-0.155(3)$ & -3.166 & $-3.785(2)$ & $-3.254^{*}$ \\
Crop area & $-1.949(3)$ & -3.166 & $-3.467(3)$ & $-3.170^{*}$ \\
\hline
\end{tabular}

Notes: values in parenthesis indicate the optimum lag length based on SBIC; "*" denote significance at the 5\%.

Table 2: ERS unit root test (with constant and trend) for rainfall and temperature

\begin{tabular}{lll}
\hline Variable & Level & Critical value \\
\hline Rainfall & $-4.679(3)$ & $-3.166^{*}$ \\
Temperature & $-2.741(3)$ & $-3.166^{*}$ \\
\hline
\end{tabular}

Notes: values in parenthesis indicate the optimum lag length based on SBIC; "*" denote significance at the 5\%.

Table 3 displays the results of the acreage response function of maize. The $\mathrm{R}^{2}$ value explains about $46 \%$ of the variations in crop area per hectare. The test result of F-statistic shows the function to be well-behaved. The results show that the first lags of maize price and rainfall are significant in explaining the variations in crop area. This means that previous year maize price and previous growing seasonal rainfall has a significant impact on current year planting decisions. The results show that, if maize prices are to increase by $1 \%$ in the previous year, farmers will increase their current crop area by $0.29 \%$. However, an increase in growing seasonal rainfall by $10 \mathrm{~mm}$ in the previous year is expected to decrease crop area by $0.37 \%$. Previous year temperature was found to have insignificant impact on current year planting decisions. A $1^{\circ} \mathrm{C}$ increase in growing season temperature last year causes a 5.6\% increase in maize acreage planted this year. The positive effect of temperature on crop area indicates that farmers increase areas allocated to maize if temperature increases in order to compensate for yield losses and obtain the desired quantity. This result is consistent with the findings of Blanc, 2011. The author investigated the impact of climate change on crop production in Sub-Saharan Africa (SSA) and found that previous year average temperature has a positive and significant relationship with current cassava acreage planted. 
Table 3: Acreage response function of maize in Ghana

\begin{tabular}{lll}
\hline $\begin{array}{l}\text { Response variable: } \log \text { (crop area) in Ha } \\
\text { Variable }\end{array}$ & Coefficient & P-value \\
\hline Intercept & $-1.074(1.052)$ & 0.314 \\
Log (crop price-1) & $0.294(0.074)$ & $0.000^{*}$ \\
(Temperature-1) & $0.056(0.039)$ & 0.161 \\
(Rainfall-1) & $-0.0037(0.0017)$ & $0.037^{*}$ \\
$\mathrm{R}^{2}$ & 0.46 & \\
F statistic & 9.79 & $0.000^{*}$ \\
\hline
\end{tabular}

Number of observation: 39

Notes: standard errors in parentheses; ${ }^{*}$ denotes significance at $1 \%$ level

Table 4 displays the quantile regression results of crop area. The results show that maize supply responds differently to previous prices and climatic variables across the different quantiles of crop area distribution. Maize supply in the $10^{\text {th }}$ quantile responds more to previous price changes compare to supply at the $95^{\text {th }}$ (upper) quantile. At the median quantile $\left(50^{\text {th }}\right), 1 \%$ rise in previous maize price will increase maize supply by $10 \%$ within that quantile. Furthermore, the effect of previous seasonal rainfall is positive at the lower quantile $\left(10^{\text {th }}\right)$ but negative at the upper quantile $\left(95^{\text {th }}\right)$. Across the different quantiles of crop area distribution, a $1{ }^{\circ} \mathrm{C}$ rise in previous seasonal temperature will increase maize supply from $2 \%$ to $13 \%$. The quantile regression results show that, the positive effect of price increase is more profound for maize supply in the lower quantiles as compared to supply at the upper quantiles. Furthermore, the sensitivity of maize supply to changes in climatic variables differs across the different quantiles of crop area distribution. Similarly, Barnwal and Kotani (2010) using yield as a proxy for supply finds that rice supply to changes to temperature and rainfall differs significantly across the quantiles of yield distribution.

Table 4: Quantile regression results using crop area as the dependent variable

\begin{tabular}{|c|c|c|c|c|c|}
\hline \multirow[t]{2}{*}{ Variable } & \multicolumn{5}{|c|}{ Quantile regression results for crop area } \\
\hline & q10 & q25 & q50 & q75 & q95 \\
\hline Intercept & $-2.79(2.44)$ & $-0.10(1.48)$ & $-0.19(2.24)$ & $-1.54(2.83)$ & $-2.29(3.50)$ \\
\hline Log (crop price-1) & $0.33(0.17)$ & $0.19(0.18)$ & $0.10(0.17)$ & $0.28(0.17)$ & $0.25(0.12)^{*}$ \\
\hline (Temperature-1) & $0.08(0.10)$ & $0.02(0.06)$ & $0.01(0.09)$ & $0.07(0.11)$ & $0.13(0.13)$ \\
\hline (Rainfall-1) & $0.001(0.004)$ & $-0.005(0.003)$ & $-0.001(0.003)$ & $-0.003(0.002)$ & $-0.007(0.002)^{*}$ \\
\hline $\mathrm{R}^{2}$ & 0.17 & 0.13 & 0.06 & 0.18 & 0.59 \\
\hline
\end{tabular}

Number of observations: 39

Notes: standard errors in parentheses; * denotes significance at $1 \%$ level.

\section{Conclusion}

The objective of this study is to study the effect of previous maize price and climatic variables on maize supply in Ghana. A lag model using the OLS technique and the quantile regression approach were employed in the study. The results of the lag regression model using the OLS technique reveal that previous maize price and rainfall significantly influences farmers maize supply decisions in Ghana. Previous seasonal temperature was found to positively influence maize supply though insignificant. The quantile regression approach indicates that maize supply responds differently to supply determinants across the various quantiles of crop area distribution. In summary the mean effects obtained in the lag model using the OLS estimation, as well as the quantile effects tends to differ. Given the differences in response across the quantiles as well as the lag model using the OLS estimation technique, a holistic view of maize supply can only be obtained if the quantile regression is used together with the lag model using OLS estimation. The study recommends that major stakeholders and policy makers should establish price support policies in the agricultural sector. Future research will consider the sensitivity of the findings of this research to alternative estimation techniques and also extend our investigations to other crops. 


\section{References}

Abdulai, A. \& Rieder, P. (1995). The impact of agricultural price policy on cocoa supply in Ghana: An error correlation estimation. Journal of African Economics, 4(3), 315-335.

Barnwal, P. \& Kotani, K. (2010). Impact of variation in climatic factors on crop yield: A case of rice in Andhra Pradesh, India. Economics and Management series 17, International University of Japan Research Institute.

Blanc, É. (2011). The impact of climate change on crop production in Sub-Saharan Africa. Unpublished Doctor of Philosophy thesis, University of Otago, Dunedin, New Zealand.

Dixit, P. K., Hiremath, K. C. \& Singh, R. J. (1998). Production behaviour of groundnut farmers in Karnataka. Indian Journal of Agricultural Economics, 53(2), 163-68.

Elliott, G., Rothenberg, T. \& Stock, J. H. (1996). Efficient tests for an autoregressive unit root. Econometrica, 64(4), 813-836.

EPA. (2000). Ghana's Initial National Communication, under the United Nations Framework Convention on Climate Change, EPA, Ghana, 160.

Jain, P. K., Singh, I. P. \& Kumar, A. (2005). Risk in Output Growth of Oilseeds in the Rajasthan State: A Policy Perspective. Agricultural Economics Research Review, 18(2).

Koenker, R. \& Bassett, G. (1978). Regression Quantiles. Econometrica, 46, 33-50.

Koenker, R. \& Bassett, G. (1982). Robust tests for heteroscedasticity based on regression quantiles. Econometrica, 50, 43-61.

Leaver, R. (2004). Measuring the Supply Response Function of Tobacco in Zimbabwe. Agrekon, 43(1).

Leider, J. (2012). A Quantile Regression Study of Climate Change in Chicago, 1960-2010. Department of Mathematics, Statistics and Computer Science, University of Illinois, Chicago.

Madhavan, M. C. (1972). Acreage response of Indian farmers - A case study of Tamil Nadu. Journal of African Economics, 27(1), 67-73.

Mamingi, N. (1996). How Prices and Macroeconomic Policies Affect Agricultural Supply and the Environment. Policy research working paper, The World Bank.

Nerlove, M. (1958a). Distributed Lags and Estimation of Long-Run Supply and Demand Elasticities: Theoretical Considerations. Journal of Farm Economics, 40: 301-311.

Patel, I. S. \& Singh, P. K. (1994). Area and yield response of bajra crop in Gujarat state. Indian Journal of Agricultural Marketing, 8(1), 87-95, 115-133.

Schwert, G. W. (1989). Tests for Unit Roots: A Monte Carlo Investigation. Journal of Business and Economic Statistics, 7, 147-160.

Singh, O. P. (1998). Growth and supply response of oil seeds in Uttar Pradesh. Agricultural Situation in India, 55(1), 3-6.

SRID/MOFA. (2010). Agriculture Statistics 2010, Statistical Research and Information Directorate, Ministry of Food and Agriculture, Ghana.

Townsend, R. F. \& Thirtle, C. (1997). Production incentives for small-scale farmers in Zimbabwe: The case of cotton and maize. Agrekon, 36(3), 251-267. 


\section{APPENDIX}

Figure A: Graphical presentation of the Unit root test for maize crop area at level and first difference.
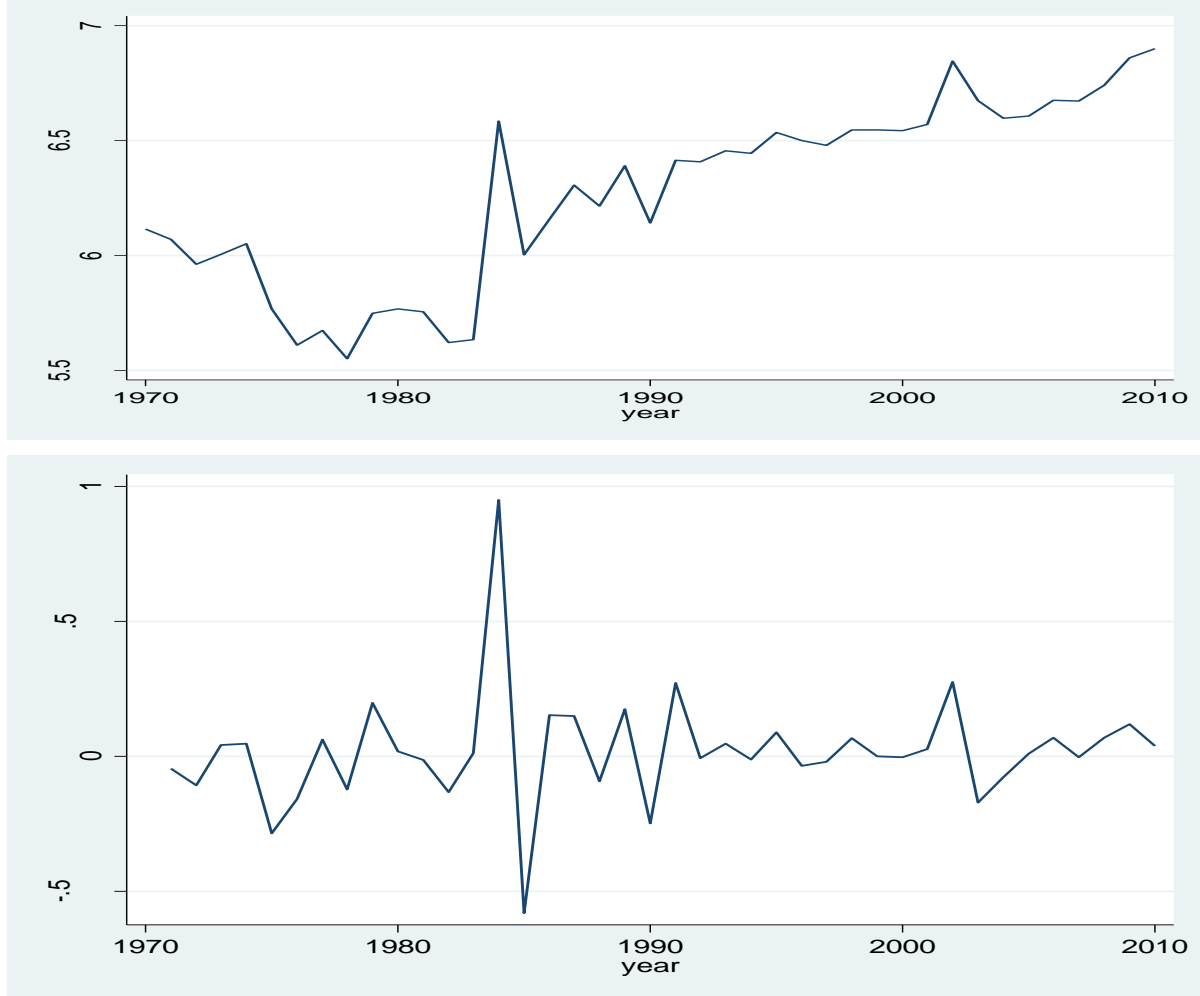

Figure B: Graphical presentation of the Unit root test for maize price at level and first difference.

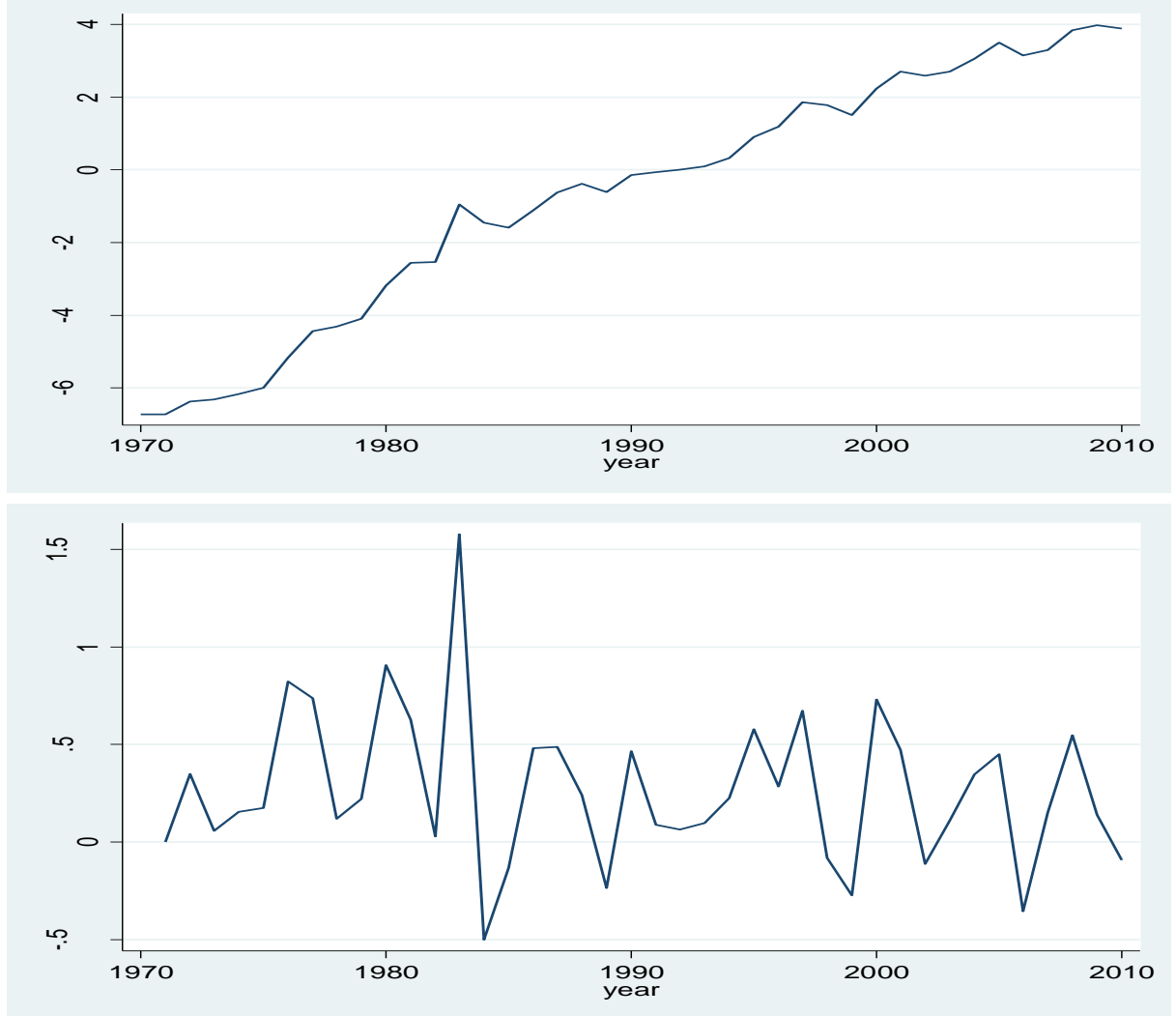


Figure C: Graphical presentation of the Unit root test for rainfall at level

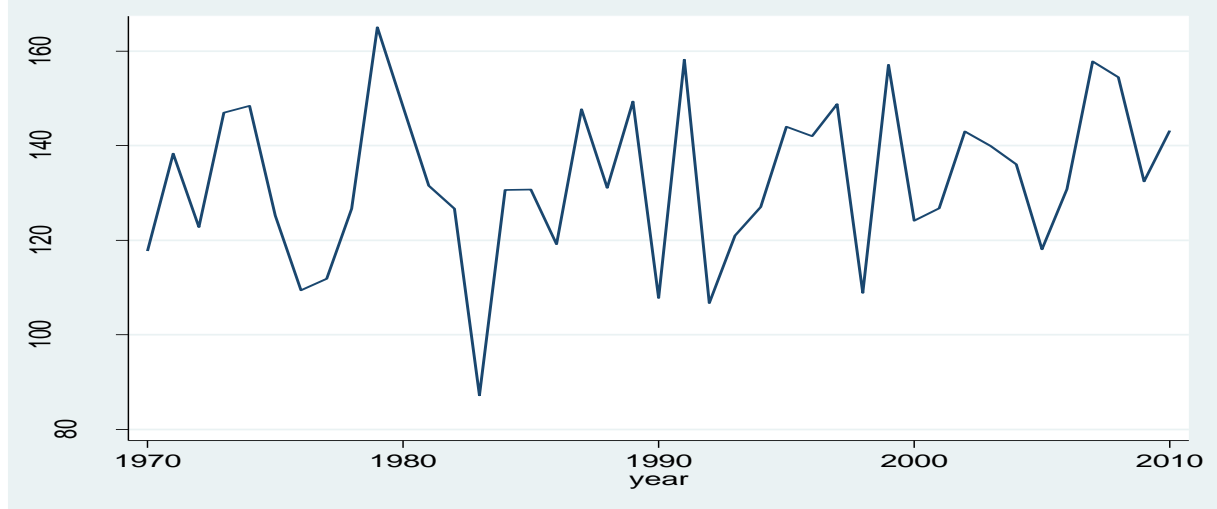

Figure D: Graphical presentation of the Unit root test for temperature at level

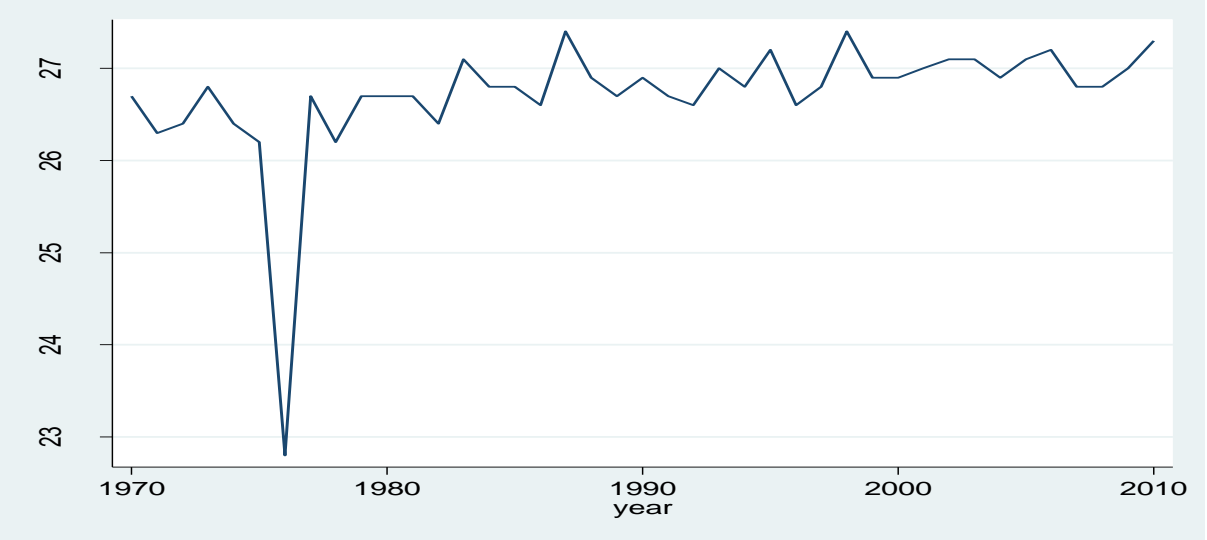

